\title{
VERIFICATION OF A HYDRODYNAMIC MODEL OF A LIQUID-PROPELLANT ROCKET ENGINE'S CAVITATING PUMPS USING EXPERIMENTAL AND THEORETICAL PUMPTRANSFER MATRICES
}

\author{
Institute of Technical Mechanics \\ of the National Academy of Sciences of U kraine and the State Space Agency of U kraine, \\ 15 Leshko-Popel St., D nipro 49005, U kraine; e-mail: dolmrut@ gmail.com
}

Cavities at the pump inlet may lead to inadmissible cavitation self-oscillations in the feed system of liquidpropellant rocket engines (LPREs) and to POGO instability if the oscillation frequency of the liquid is close to that of the rocket structure. Because of this, it is important to prevent both cavitation and POGO oscillations as early as at the engine and rocket design stage. This calls for a reliable mathematical model of the dynamics of LPRE cavitating pumps. In this paper, a hydrodynamic model of LPRE cavitating pumps is verified using theoretical and experimental transfer matrices of cavitating pumps. The experimental transfer matrix was borrowed from Brennen, Meissner, Lo, and Hoffman's work because it features the least spread of values among the matrices reported in the literature. The theoretical matrix was borrowed from Pilpenko and Kvasha's work where is was constructed for a cavitating pump as a distributed-parameter system. Four versions of the hydrodynamic model of LPRE cavitating pumps are verified, and six possible model coefficients are considered. Only one coefficient, namely, the liquid inertance at the cavity location, takes a physically meaningless negative value, which makes its use impossible. The verification results show that a four-coefficient model of cavitating pipe dynamics adequately describes cavitation effects in LPRE pumps over the frequency range up to $200 \mathrm{~Hz}$. The four coefficients are the cavitation elasticity, the cavitation resistance, the cavity-caused disturbance transfer delay time, and the cavity time constant or the cavitation resistance distribution coefficient.

Keymords liquid-propellant rocket engine, inducer-equipped centrifugal pump, cavitation, transfer matrix, hydrodynamic model, delay element, verification.

1. Borovsky B. I., Ershov N. S., Ovsyannnikov B. V., Petrov V. I., Chebaevsky V. F., Shapiro A. S. High-Speed Blade Pumps. Moscow: Mashinostroyeniye, 1975. 336 pp. (in Russian).

2. Pilipenko V. V., Zadontsev V. A., Natanzon M. S. Cavitation Oscillations and Hydrosystem Dynamics. Moscow: Mashinostroyeniye, 1977. 352 pp. (in Russian).

3. Kolesnikov K. S. POGO Oscillations of a Liquid-Propellant Rocket. Moscow: Mashinostroyeniye, 1971. 260 pp. (in Russian).

4. Pilipenko V. V. Calculation-and-experiment method for determining the compliance and volume of cavities in inducer-equipped centrifugal pumps. Izvestiya AN SSSR. Energetika i Transport. 1976. No. 3. Pp. 131-139. (in Russian).

5. Brennen C. E., Meissner C., Lo E. V., Hoffman G. S. Scale effects in the dynamic transfer functions for cavitating inducers. Transactions of the ASME. 1982. V. 104. Pp. 428-433.

https://doi.org/10.1115/1.3241875

6. Pilipenko V. V., Kvasha Yu. A. Stability of cavity flow past a plate cascade. Teh. Meh. 2001. No. 2. Pp. 144-149. (in Russian).

7. Pylypenko O.V., Prokopchuk A. A., Dolgopolov S. I., Pisarenko V. Yu., Kovalenko V. N., Nikolaev A. D., Khoryak N. V. Pequliarities of mathematical modeling of low-frequency dynamics of the staged liquid rocket sustainer engines at its startup. Space Sci.\&Technol. 2017. V. 23. No. 5. Pp. 3-12. (in Russian).

https://doi.org/10.15407/knit2017.05.003

8. Pylypenko O.V., Prokopchuk A. A., Dolgopolov S. I., Khoryak N. V., . ., Nikolaev A. D., Pisarenko V. Yu., Kovalenko V. N. Mathematical simulation and stability analysis of low-frequency processes in a staged-combustion liquid-propellant sustainer engine. Vestnik Dvigatelestroyeniya. 2017. No. 2. Pp. 34-42. (in Russian).

9. $\mathrm{Ng} \mathrm{S}$. L., Brennen C. Experiments of the dynamic behavior of cavitating pumps. Journal of Fluids 
Engineering. 1978. V. 100. No. 2. Pp. 166-176.

https://doi.org/10.1115/1.3448625

10. Kawata Y., Ebara K., Uehara S., Takata T. System instability caused by the dynamic behaviour of a centrifugal pump at partial operation. JSME International J. 1987. V.30. No. 260. Pp. 271-278. https://doi.org/10.1299/jsme1987.30.271

11. Kawata Y., Takata T., Uehara S., Yasuda O., Yoshino H., Takeuchi T. Prediction of system instability by measuring the dynamic characteristics of prototype multistage centrifugal pump. Technical Review. 1988. V. 25. No. 3. Pp. 160-164.

12. Stirnemann A., Eberl J., Bolleter U., Pace S. Experimental determination of the dynamic transfer matrix for a pump. Journal of Fluids Engineering. 1987. V. 109. No. 3. Pp. 218-225. https://doi.org/10.1115/1.3242651

13. Shimura T., Kamijo K., Yamade A. Dynamic response of a liquid oxygen pump of the LE-5 rocket engine. Proc. 13 th. lut. Symp. Space Technol. and Sci. Tokyo. 1982. Pp. 307-313.

14. Pilipenko V. V., Kvasha Yu. A. Cavity flow past a plate cascade. Izvestiya AN SSSR. Energetika i Transport. 1991. No. 3. Pp. 139-143. (in Russian).

15. Pilipenko V. V., Kvasha Yu. A., Fomenko P. V. Frequency behavior of an inducer-equipped centrifugal pump in partial cavitation. Izvestiya AN SSSR. Energetika i Transport. 1991. No. 5. Pp. 135-141. (in Russian).

Received on September 7, 2020, in final form on September 21, 2020 